\title{
Beryllium ion sensing through the ion pair formation between the electrochemically reduced ferrocenyl naphthoquinone radicals and $\mathrm{Be}^{2+}$ ions
}

\author{
SECIL KIRLANGIC ATASEN, YUSUF ALCAY, OZGUR YAVUZ, BARIS YUCEL and \\ ISMAIL YILMAZ* (D) \\ Department of Chemistry, Istanbul Technical University, 34469 Maslak, Istanbul, Turkey \\ E-mail: iyilmaz@itu.edu.tr
}

MS received 15 January 2019; revised 7 March 2019; accepted 13 March 2019; published online 9 May 2019

\begin{abstract}
We explored the mechanistic aspects of ion pair formation between electrochemically reduced radicals $\left(\mathbf{F c}-\mathbf{c n q}-\mathbf{1 a ^ { \bullet } -} / \mathbf{F c}-\mathbf{c n q}-\mathbf{1 b}^{\bullet-}\right)$ and dianions $\left(\mathbf{F c}-\mathbf{c n q}-\mathbf{1 a}^{2-} / \mathbf{F c}-\mathbf{c n q}-\mathbf{1 b}^{2-}\right)$ of ferrocenyl naphthoquinones (Fc-cnq-1a and Fc-cnq-1b) and several metal ions by cyclic voltammetry (CV), square wave voltammetry (SWV) and spectroelectrochemistry, for the first time. The experiments demonstrated that Fc-cnq-1 $\mathbf{a}^{2-} / \mathbf{F c}-\mathbf{c n q}-\mathbf{1} \mathbf{b}^{2-}$ were moderately affected with $\mathrm{Na}^{+}, \mathrm{K}^{+}$and $\mathrm{Cs}^{+}$by slightly shifting to the anodic side, but were strongly influenced with $\mathrm{Li}^{+}$ion. $\mathbf{F c}-\mathbf{c n q}-\mathbf{1 a}^{\bullet}-\mathbf{F} \mathbf{c}-\mathbf{c n q}-\mathbf{1 b}^{\bullet}{ }^{-}$- were not affected by alkali metal ions, indicating no ion pair formation between the radicals and these ions. Fc-cnq-1a ${ }^{2-} / \mathbf{F c}-\mathbf{c n q}-\mathbf{1} \mathbf{b}^{2-}$ was not evolved in the presence of $\mathrm{Be}^{2+}, \mathrm{Mg}^{2+}$ and $\mathrm{Ca}^{2+}$, but $\mathbf{F c}-\mathbf{c n q}-\mathbf{1 a} \mathbf{a}^{\mathbf{-}}-\mathbf{F} \mathbf{c}-\mathbf{c n q}-\mathbf{1} \mathbf{b}^{\bullet-}$ appeared with their cathodic waves, and participated with intermediates, $\left[(\mathbf{F} \mathbf{c}-\mathbf{c n q}-\mathbf{1} \mathbf{b})_{2}{ }^{\bullet}{ }^{-}-\mathbf{B e}^{2+}\right.$ and $\left[(\mathbf{F} \mathbf{c}-\mathbf{c n q} \mathbf{- 1 a})^{\bullet}-\mathbf{- C l}\right]$. The

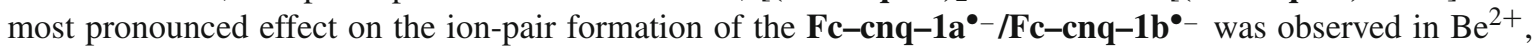
indicating that $\mathbf{F c - c n q - 1 a}$ or $\mathbf{F c - c n q - 1 b}$ can selectively sense ultra-trace amount of $\mathrm{Be}^{2+}(\mathrm{LOD}=3.6 \mathrm{ppb})$ among the other metal ions with SWV titration, for the first time, based on the strong ion pair formation reaction between the radicals and $\mathrm{Be}^{2+}$.
\end{abstract}

Keywords. Beryllium; ion pair formation; naphthoquinone; metal sensor; spectro-electrochemistry.

\section{Introduction}

It is well-known that many quinones exhibit two successive one-electron reduction processes in a dry organic aprotic solvent. The first chemically reversible process at $E_{1}$ yields a monoanion radical (semiquinone) product and the second generally at least quasi-reversible process at a more negative potential, $E_{2}$, produces dianion species at customary scan speeds. ${ }^{1-5}$ The potentials of these reductions depend on the polarity of solvents, the nature of the supporting electrolyte and the presence of acidic additives, reflecting respectively non-specific solvation energies, ion-pairing and protonation. ${ }^{1-5}$ Few studies have been devoted to exploring the ion-pair formation processes between the electrochemically reduced quinones and the cationic species, including some alkali metals and alkaline earth metal cations in aprotic solvents. ${ }^{6-9}$ For these studies, some well-known electrochemical methods such as cyclic voltammetry (CV) and pulse-electrolysis stopped-flow were used to explore the mechanistic aspects of the electrochemical reduction of quinones in the presence of metal ions such as $\mathrm{Na}^{+}, \mathrm{Mg}^{+2}$ and $\mathrm{Ba}^{+2}$. However, there is no comprehensive study in the literature to investigate the mechanism of the ion pair formation between electrochemically reduced quinones and alkali, alkaline earth metal and transition metals in a combined form. Moreover, as far as we know, spectroelectrochemistry has not been implemented to explain this mechanism.

In this study, firstly, we investigated the ion pair formation between the electrochemically reduced monoanion radicals/dianion products $\left(\mathbf{F c}-\mathbf{c n q}-\mathbf{1 a} \mathbf{a}^{\bullet}-\mathbf{F c}-\mathbf{c n q}-\right.$ $\mathbf{1 b}^{\bullet-}$ and $\left.\mathbf{F c}-\mathbf{c n q}-\mathbf{1} \mathbf{a}^{2-} / \mathbf{F c}-\mathbf{c n q}-\mathbf{1} \mathbf{b}^{2-}\right)$ of ferrocenyl naphthoquinones (Fc-cnq-1a and Fc-cnq-1b) and

\footnotetext{
*For correspondence

Electronic supplementary material: The online version of this article (https://doi.org/10.1007/s12039-019-1616-7) contains supplementary material, which is available to authorized users.
} 


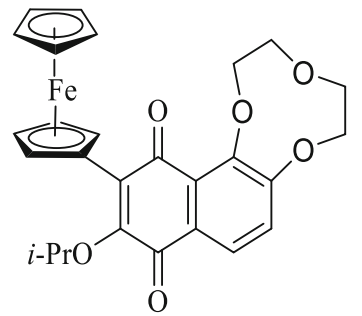

Fc-cnq-1a

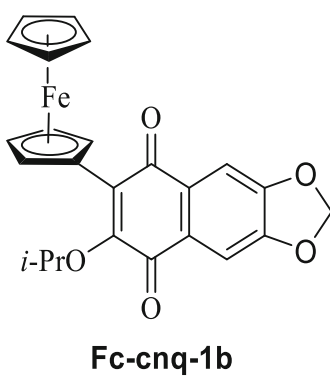

Figure 1. Structures of the molecules Fc-cnq-1a and Fc-cnq-1b.

several metal ions $\left(\mathrm{Li}^{+}, \mathrm{Na}^{+}, \mathrm{K}^{+}, \mathrm{Cs}^{+}, \mathrm{Be}^{2+}, \mathrm{Mg}^{2+}\right.$, $\mathrm{Ca}^{2+}, \mathrm{Ba}^{2+}, \mathrm{Ni}^{2+}, \mathrm{Zn}^{2+}, \mathrm{Cu}^{2+}$ and $\mathrm{Co}^{2+}$ ) by cyclic voltammetry, square wave voltammetry (SWV) and in situ spectroelectrochemistry in a thin layer cell. The reasons behind choosing the ferrocenyl naphthoquinone fused crown ether Fc-cnq-1a and model compound Fc-cnq-1b without crown ether unit in the molecular structure (Figure 1) are as follows: (1) the naphthoquinone skeletal structure provides electron transfer processes with tunable redox potential in the presence of metal ions along with thermal and chemical stability: ${ }^{4,10-14}$ (2) ferrocene unit in the molecular structure of Fc-cnq-1a and Fc-cnq-1b displays well-known one-electron reversible oxidation process which can serve as an internal electrochemical standard to evaluate ion pair formation; (3) the crown ether unit not only makes the compound Fc-cnq-1a highly soluble but also provides information about the ion pair formation mechanism only taking place between the reduced naphthoquinone products and metal ions, although it is capable of complex formation with proper metal ions; (4) the naphthoquinone fused crown ether Fc-cnq-1a as a triad molecule shows intramolecular charge-transfer (ICT) transition between the ferrocenyl donor and the naphthoquinonyl acceptor center $\left[\mathrm{e}_{\pi}(\mathrm{HOMO}-\mathrm{Fc}) \rightarrow\right.$ $\mathrm{e}_{\pi *}$ (LUMO-cnq)] at near IR region, which renders monitoring spectral changes of the molecules during the electrolysis in thin layer cell, thereby understanding the ion pair formation reaction.

In the second part of this study, based on the ion pair formation between the electrochemically reduced monoanion radical products $\left(\mathbf{F c}-\mathbf{c n q}-\mathbf{1 a}^{\bullet}-\mathbf{F c}-\right.$ cnq-1 $\mathbf{b}^{\mathbf{-}}$ ) and several metal ions, we demonstrate that the molecules Fc-cnq-1a and Fc-cnq-1b could serve as electrochemical $\mathrm{Be}^{2+}$ ion sensors among the studied metal ions. Beryllium (Be) is extremely harmful to health and is the most toxic element without radioactivity. However, it is widely used for defence materials, aerospace, nuclear energy and weapons, electronics and communications, and automobile manufacturing. ${ }^{15} \mathrm{Be}$ can lead to an immune system failure known as Be sensitization, and can cause documented illnesses of chronic Be disease (CBD) or berylliosis, an incurable and potentially fatal progressive lung ailment. ${ }^{16-20}$ International Agency for Research on Cancer (IARC) ${ }^{21}$ and the World Health Organization (WHO) ${ }^{22}$ have underlined the carcinogenic risks of $\mathrm{Be}$ and its compounds for humans. Despite the scarcity of Be in the earth's crust $\left(2.8-5.0 \mu \mathrm{g} . \mathrm{g}^{-1}\right)$, water supplies and atmosphere are contaminated by Be via discharges from anthropogenic sources. ${ }^{22}$ Hence, sensitively determination of Be is very important for environmental protection and human health. $\mathrm{Be}^{2+}$ ion in the different samples have been determined with varying analytical techniques, e.g., spectrophotometry, ${ }^{23-25}$ gravimetry, ${ }^{26}$ chromatography, ${ }^{27-29}$ spectrofluorimetry, ${ }^{30}$ gas chromatography, ${ }^{31}$ atomic absorption spectrometry (AAS), ${ }^{32}$ inductively coupled plasma mass spectrometry (ICP-MS), ${ }^{33}$ and electrothermal atomic absorption spectrometry (ETAAS). ${ }^{34}$ However, most of these methods are timeconsuming, and relatively expensive. Therefore, electrochemical methods can be preferred because of cheap, sensitive and practical methods to determine ultra-trace amount of $\mathrm{Be}^{2+} \cdot 15$

In the present work, a simple and sensitive electrochemical method was developed for the determination of $\mathrm{Be}^{2+}$ using $\mathrm{SWV}$ through the ion pair formation between the electrochemically reduced monoanion radical products $\left(\mathbf{F c}-\mathbf{c n q}-\mathbf{1 a}^{\bullet-} / \mathbf{F c}-\mathbf{c n q}-\mathbf{1 b}^{\bullet-}\right)$ and $\mathrm{Be}^{2+}$. In the past studies, although trace amount of $\mathrm{Be}^{2+}$ was determined by using adsorptive stripping voltammetry and adsorption voltammetry based on the polymericelectrosensor, ${ }^{15,35-37}$ the ion-pair formation process is facilitated for the first time to determine ultra-trace amount of $\mathrm{Be}^{2+}$ in our study.

\section{Experimental}

\subsection{Chemicals}

Fc-cnq-1 $\mathbf{a}^{10}$ and $\mathbf{F c - c n q - 1 \mathbf { b } ^ { 5 }}$ studied herein were previously synthesized by our research group. All reagents were used as purchased from a commercial supplier (Sigma Aldrich) without further purification unless otherwise indicated. Tetra- $n$-butylammonium perchlorate used as supporting electrolyte $\left(n-\mathrm{Bu}_{4} \mathrm{NClO}_{4}\right.$, Fluka Chemical Co.) was recrystallized from ethyl alcohol and dried in a vacuum oven at $40{ }^{\circ} \mathrm{C}$ for at least 1 week prior to use. Analytical grade $\mathrm{Be}^{2+}$ solution was prepared from its chloride salt and $\mathrm{Li}^{+}$, $\mathrm{Na}^{+}, \mathrm{K}^{+}, \mathrm{Cs}^{+}, \mathrm{Mg}^{2+}, \mathrm{Ca}^{2+}, \mathrm{Ba}^{2+}, \mathrm{Ni}^{2+}, \mathrm{Cu}^{2+}, \mathrm{Co}^{2+}$ and $\mathrm{Zn}^{2+}$ solutions were prepared from their perchlorate salts. 

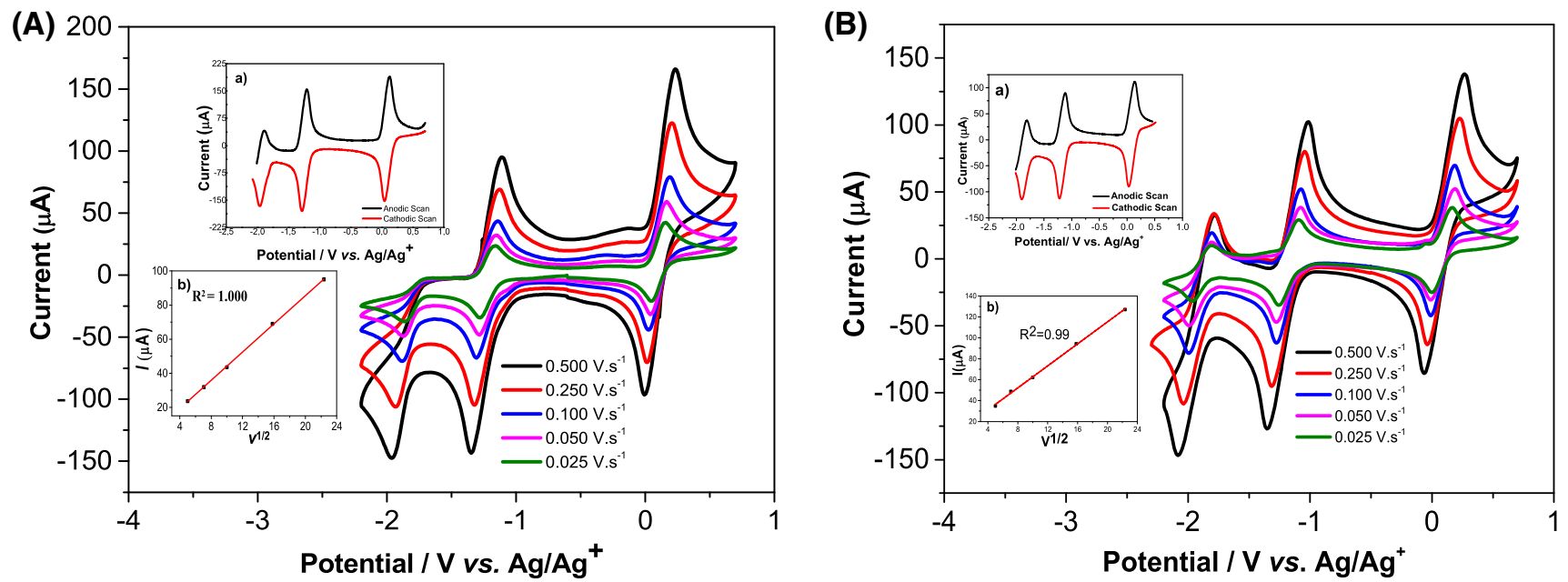

Figure 2. CVs of Fc-cnq-1a (A) and Fc-cnq-1b (B) in DMF solution containing $0.2 \mathrm{M} n$ - $\mathrm{Bu}_{4} \mathrm{NClO}_{4}$ at different scan rates $\left(0.025 \mathrm{~V} \mathrm{~s}^{-1}-0.500 \mathrm{~V} \mathrm{~s}^{-1}\right)$. Inset a: SWVs of Fc-cnq-1a and Fc-cnq-1b. For SWV Pulse PH/PW: $0.025 \mathrm{~V}$ for 0.01 s; Step Height: $2.00 \mathrm{mV}$; Scan rate: 0.100. Inset b: Plot of $v^{1 / 2}$ vs first reduction cathodic peak current. Working electrode: glassy carbon disk electrode (3.0 mm diameter). The concentrations of Fc-cnq-1a and Fc-cnq-1b $=5.0 \times 10^{-3} \mathbf{M}$.

\subsection{Measurements}

Cyclic (CV) and Square Wave Voltammetry (SWV) were carried out by a Princeton Applied Research model 2263 potentiostat controlled by an external PC. A three-electrode system [BAS model (Bioanalytical System Inc.) solid cell stand] was used for CV and SWV measurements in DMF, and it consisted of glassy carbon $(3.0 \mathrm{~mm}$ diameter $)$ disc electrodes as the working electrode, a platinum wire counter electrode, and an $\mathrm{Ag} / \mathrm{AgNO}_{3}$ (non-aqueous) reference electrode. The reference electrode separated from the bulk solutions containing Fc-cnq-1a and Fc-cnq-1b were deoxygenated by a stream of high purity argon for $35 \mathrm{~min}$ before running the experiment, and the solution was protected from air by a blanket of argon during the experiment. The sample and solvent were placed into the electrolysis cell under argon. In situ UV-vis, spectroelectrochemical experiments were performed with a home-built thin-layer cell that utilized a light transparent platinum gauze working electrode. ${ }^{38}$ Potentials were applied and monitored with a Princeton Applied Research model 2263 potentiostat. Time-resolved UV-vis spectra were recorded on an Agilent model 8453 diode array spectrophotometer.

\section{Results and Discussion}

\subsection{Mechanistic aspects of ion pair formation}

The mechanistic aspects of the ion pair formation between the electrochemically reduced products of naphthoquinones Fc-cnq-1a and Fc-cnq-1b and several metal ions $\left(\mathrm{Li}^{+}, \mathrm{Na}^{+}, \mathrm{K}^{+}, \mathrm{Cs}^{+}, \mathrm{Be}^{2+}, \mathrm{Mg}^{2+}, \mathrm{Ca}^{2+}\right.$, $\mathrm{Ba}^{2+}, \mathrm{Ni}^{2+}, \mathrm{Zn}^{2+}, \mathrm{Cu}^{2+}$ and $\mathrm{Co}^{2+}$ in DMF were comparatively investigated in detail by voltammetric titration technique. In this part of the study, first, the routine electrochemical behavior of Fc-cnq-1a and Fc-cnq1b was investigated by $\mathrm{CV}$ in the presence of $0.2 \mathrm{M}$ tetra- $n$-butylammonium perchlorate $\left(n-\mathrm{Bu}_{4} \mathrm{NClO}_{4}\right)$ as a supporting electrolyte in DMF. Figure 2 shows the CVs of Fc-cnq-1a (A) and Fc-cnq-1b (B) in the scan rates between 0.025 and $0.500 \mathrm{~V} . \mathrm{s}^{-1}$, where SWVs of Fccnq-1a and $\mathbf{F c - c n q - 1 b}$ and the plot of $I \mathrm{c} v s$. square root of scan rate $\left(v^{1 / 2}\right)$ for the first reduction process are represented as insets $a$ and $b$, respectively. It can be seen that Fc-cnq-1a exhibits chemically reversible one-electron reduction process to form semiquinone radical product, monoanion Fc-cnq-1a'- at $E_{1 / 2}^{(1)}=-1.22 \mathrm{~V}\left[\Delta E_{\mathrm{p}}\right.$ (the anodic to cathodic peak-to-peak separation $)=0.095 \mathrm{~V}$, $I_{\mathrm{pa}} / I_{\mathrm{pc}}$ (the anodic-cathodic peak ratio) $\left.=0.98\right]$. Following one-electron reduction is observed at more negative potential as a quasi-reversible process at $E_{1 / 2}^{(2)}=$ $-1.78 \mathrm{~V}\left[\Delta E_{\mathrm{p}}=0.110 \mathrm{~V}, I_{\mathrm{pa}} / I_{\mathrm{pc}}=0.50\right]$ to form the doubly reduced product, dianion $\mathbf{F c}-\mathbf{c n q}-\mathbf{1 a}^{2-}$ at a scan rate of $0.050 \mathrm{~V} \mathrm{~s}^{-1}$ (magenta line in Figure 2A). Fc-cnq-1a also displays chemically reversible oneelectron oxidation process corresponding to the ferrocenium/ferrocene $\left(\mathbf{F c}^{+}\right.$-cnq-1a/Fc-cnq-1a) couple at $E_{1 / 2}^{(F c)}=0.102 \mathrm{~V}\left(\Delta E_{\mathrm{p}}=0.096 \mathrm{~V}, I_{\mathrm{pa}} / I_{\mathrm{pc}}=1.0\right)$. The reaction mechanism corresponding to the reduction and the oxidation processes is represented in Scheme 1.

The processes are similar to typical CVs of benzoquinone, naphthoquinone, and ferrocene derivatives in aprotic organic solvents without water and acidic ingredients. ${ }^{4,5,39-41}$ On the other hand, the electrochemistry of Fc-cnq-1b is similar to that of Fc-cnq-1a under the same conditions (Figure 2B). Compared to the CVs of Fc-cnq-1a (blue line) and Fc-cnq-1b (red line) in Figure 3, the first reduction potential of 

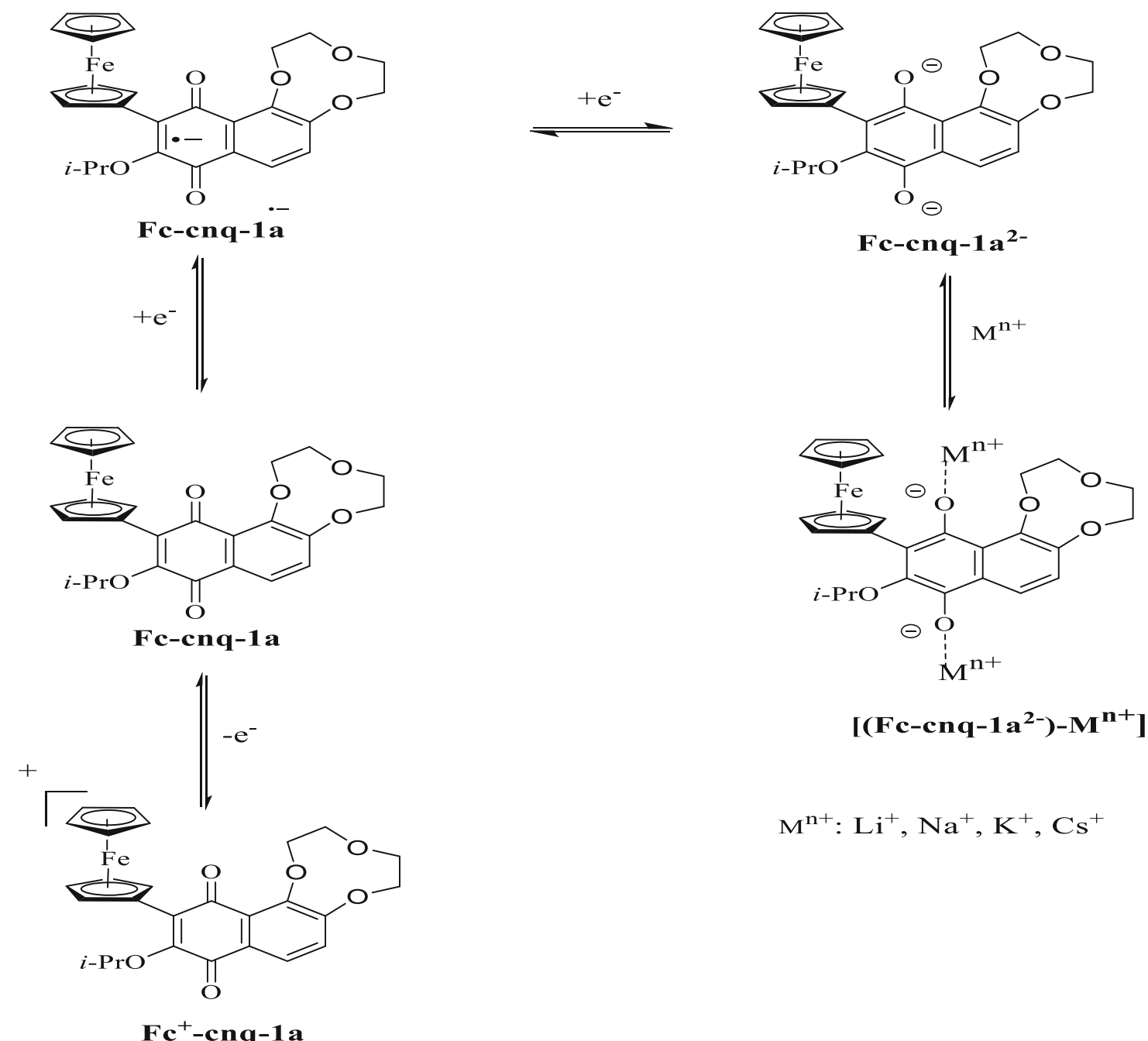

$$
\left[\left(\mathbf{F c}-\mathbf{c n q}-1 \mathbf{a}^{2-}\right)-\mathbf{M}^{\mathbf{n}+}\right]
$$$$
\mathrm{M}^{\mathrm{n}+}: \mathrm{Li}^{+}, \mathrm{Na}^{+}, \mathrm{K}^{+}, \mathrm{Cs}^{+}
$$

Scheme 1. The representative mechanism of the electrochemical processes for Fc-cnq-1a, and the ion pair formation between the dianion $\mathbf{F c}-\mathbf{c n q}-\mathbf{1 a}^{2-}$ and alkali metal ions $\left(\mathrm{Li}^{+}, \mathrm{Na}^{+}, \mathrm{K}^{+}\right.$and $\left.\mathrm{Cs}^{+}\right)$in $\mathrm{DMF}$.

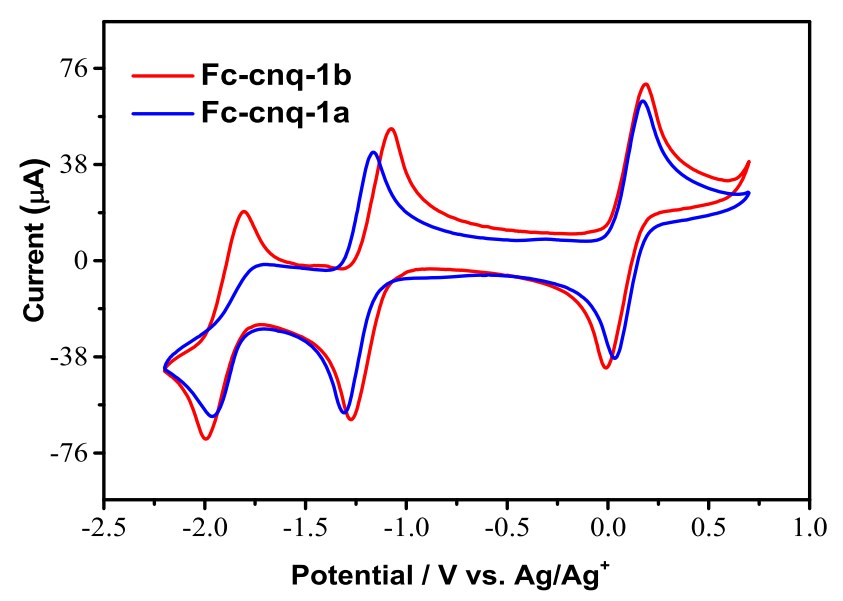

Figure 3. CVs of Fc-cnq-1a (blue line) and Fc-cnq-1b (red line) in DMF containing $0.2 \mathrm{M} n-\mathrm{Bu}_{4} \mathrm{NClO}_{4}$ at scan rate of $0.100 \mathrm{~V} \mathrm{~s}^{-1}$, the concentration of Fc-cnq-1a and Fc-cn$\mathrm{q}-1 \mathrm{~b}=5.0 \times 10^{-3} \mathrm{M}$. Working electrode: glassy carbon disk electrode (3.0 $\mathrm{mm}$ diameter).
Fc-cnq-1a shifted to the cathodic region because of more electron-donating oxygen atoms in case of $\mathbf{F c -}$ cnq-1a.

The loss of the current observed for the second reduc-

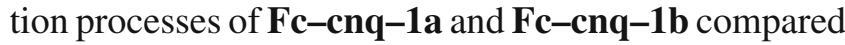
to the first reduction processes is probably due to a complexation reaction between the doubly reduced product (Fc-cnq-1a ${ }^{2-}$ or Fc-cnq-1 $\mathbf{b}^{2-}$ ) and neutral state of the molecules or an adsorption of the reduced species on the electrode surface, which was previously reported for several quinones in aprotic media. ${ }^{1}$ The differences between the half-wave potentials of the first oxidation and the first reduction processes $\left({ }^{1} \Delta E_{\mathrm{p}}\right)$ of $\mathbf{F c}-\mathbf{c n q}-\mathbf{1 a}$ and $\mathbf{F c - c n q - 1 b}$, related to the energy of the CT between the ferrocenyl donor and naphthoquinonyl acceptor centers $\left[\mathrm{e}_{\pi}(\mathrm{HOMO}-\mathrm{Fc}) \rightarrow \mathrm{e}_{\pi *}(\mathrm{LUMO}-\mathrm{cnq})\right]$, were found to be $1.32 \mathrm{~V}$ and $1.26 \mathrm{~V}$, respectively. The differences between the half-wave potentials of the first and the 
(a)

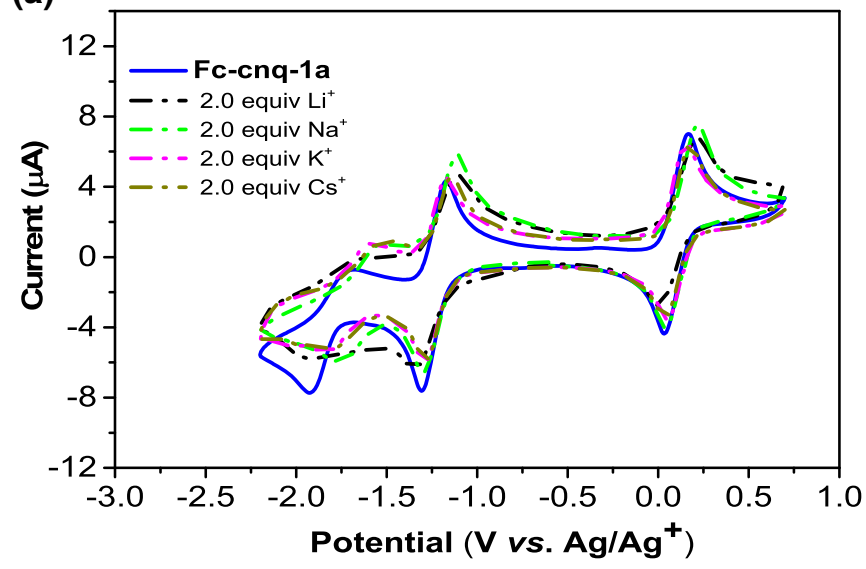

(b)

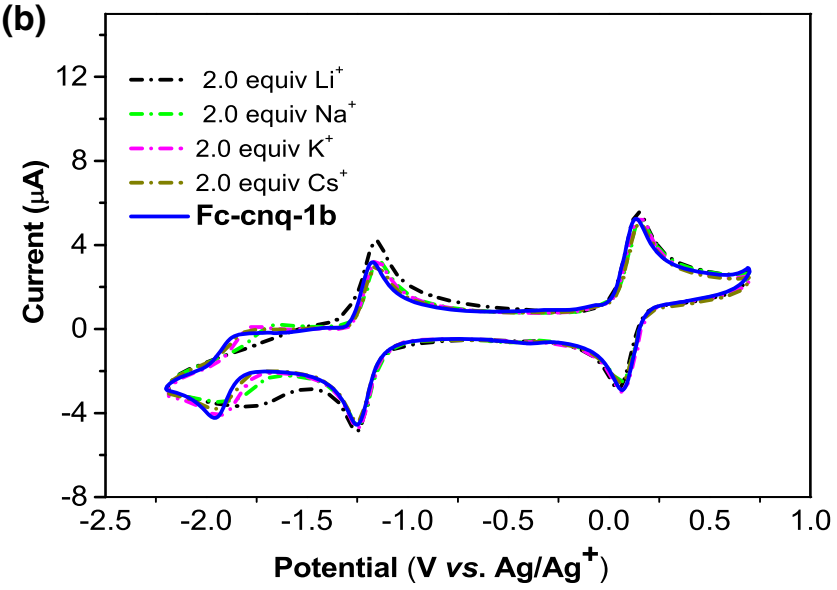

Figure 4. CVs of Fc-cnq-1a (a) and Fc-cnq-1b (b) in the presence of 2.0 equiv. alkali metal $\left(\mathrm{Li}^{+}, \mathrm{Na}^{+}, \mathrm{K}^{+}\right.$and $\left.\mathrm{Cs}^{+}\right)$ perchlorates in DMF solution containing $0.2 \mathrm{M} \mathrm{n}$-Bu $\mathrm{BClO}_{4}$ at scan rate of $0.100 \mathrm{~V} \mathrm{~s}^{-1}$, the concentration of $\mathbf{F c}-\mathbf{c n q}-\mathbf{1 a}$ and $\mathbf{F} \mathbf{c}-\mathbf{c n q}-\mathbf{1 b}=5.0 \times 10^{-3} \mathrm{M}$. Working electrode: glassy carbon disk electrode (3.0 mm diameter).

second reduction processes $\left({ }^{2} \Delta E_{\mathrm{p}}\right)$ for $\mathbf{F c - c n q - 1 a}$ and Fc-cnq-1b were calculated as 0.56 and $0.72 \mathrm{~V}$, respectively. The ${ }^{1} \Delta E \mathrm{p}$ and ${ }^{2} \Delta E \mathrm{p}$ values of $\mathbf{F c - c n q - 1 a}$ and Fc-cnq-1b showed a good agreement with those of the ferrocenyl naphthoquinones bearing different substituents in the same experimental conditions. ${ }^{4,5}$

For the ferrocene molecule, under our experimental conditions, $E_{1 / 2}$ of $\mathrm{Fc}^{+} / \mathrm{Fc}$ was calculated as $E_{1 / 2}=$ $0.069 \mathrm{~V}\left(\Delta E_{\mathrm{p}}=0.085 \mathrm{~V}\right)$ at the scan rate of $0.100 \mathrm{~V} \mathrm{~s}^{-1}$, which can be used as a criterion for electrochemical reversibility. ${ }^{5,42-44}$ The redox processes of Fc-cnq-1a

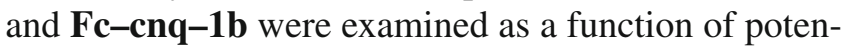
tial scan rate in order to ascertain the mode of mass transport. The cathodic and anodic currents for the oxidation and reduction couples in DMF increased in direct proportion to the square root of scan rates between 0.025 and $0.500 \mathrm{~V} \mathrm{~s}^{-1}$. Thus, this implied that the redox reactions in the solution were controlled by diffusion ${ }^{5,42-44}$ (insets $b$ in Figure 2). Second, the ion pair formation between electrochemically reduced products $(\mathbf{F c}-\mathbf{c n q}-$ $\mathbf{1 a}^{\bullet}-\mathbf{F c}-\mathbf{c n q}^{-1 \mathbf{b}^{-}}{ }^{-}$and $\mathbf{F c}-\mathbf{c n q}-\mathbf{1 \mathbf { a } ^ { 2 - }} / \mathbf{F c}-\mathbf{c n q}-\mathbf{1 b}^{2-}$ ) and several metal ions $\left(\mathrm{Li}^{+}, \mathrm{Na}^{+}, \mathrm{K}^{+}, \mathrm{Cs}^{+}, \mathrm{Be}^{2+}, \mathrm{Mg}^{2+}\right.$, $\mathrm{Ca}^{2+}, \mathrm{Ba}^{2+,} \mathrm{Ni}^{2+}, \mathrm{Zn}^{2+}, \mathrm{Cu}^{2+}$ and $\mathrm{Co}^{2+}$ ) were investigated in detail by voltammetric titration technique using $\mathrm{CV}$ at scan rate of $0.100 \mathrm{~V} \mathrm{~s}^{-1}$ in the presence of $0.2 \mathrm{M}$ tetra- $n$-butyl- ammonium perchlorate $\left(n-\mathrm{Bu}_{4} \mathrm{NClO}_{4}\right)$ as a supporting electrolyte in DMF. The CVs obtained from voltammetric titrations of Fc-cnq-1a and Fc-cnq-1b with alkali metal $\left(\mathrm{Li}^{+}, \mathrm{Na}^{+}, \mathrm{K}^{+}\right.$, and $\left.\mathrm{Cs}^{+}\right)$perchlorates in DMF are separately represented in Figures $1 \mathrm{~S}-4 \mathrm{~S}$. To be able to compare better, the CVs of Fc-cnq-1a and Fc-cnq-1b in the presence of 2.0 equiv. alkali metal perchlorates are combined in Figure 4. As seen from Figure 4, Fc-cnq-1a and Fc-cnq-1b displayed almost similar electrochemical behavior in the presence of 2.0 equiv. alkali metal $\left(\mathrm{Li}^{+}, \mathrm{Na}^{+}, \mathrm{K}^{+}\right.$and $\left.\mathrm{Cs}^{+}\right)$ ions.

The model compound Fc-cnq-1b in the absence of alkali metal ions exhibited the cathodic peak potentials at $-1.96 \mathrm{~V}$ corresponding to the dianionic species $\mathbf{F c}$ $\mathbf{c n q}-\mathbf{1} \mathbf{b}^{2-}$ while $\mathbf{F c - c n q} \mathbf{- 1} \mathbf{b}$ in the presence of 2.0 equiv. $\mathrm{Li}^{+}, \mathrm{Na}^{+}, \mathrm{K}^{+}$and $\mathrm{Cs}^{+}$ions, displayed the cathodic peak potentials at $-1.79 \mathrm{~V},-1.91 \mathrm{~V},-1.95 \mathrm{~V}$ and $-1.95 \mathrm{~V}$, respectively for the same dianionic species. The differences of the cathodic peak potentials between Fc-cnq-1b in the absence and presence of $\mathrm{Li}^{+}, \mathrm{Na}^{+}, \mathrm{K}^{+}$ and $\mathrm{Cs}^{+}$ions were calculated as $0.17 \mathrm{~V}, 0.05 \mathrm{~V}, 0.01 \mathrm{~V}$ and $0.01 \mathrm{~V}$, respectively. As seen from this comparison, the peak potentials corresponding to the dianionic

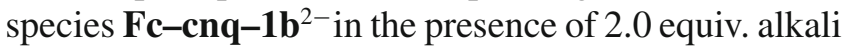
metal ions shifted to anodic region relative to that of Fc-cnq-1b in the absence of alkali metal ions, probably due to the ion pair formation reaction between the dianionic species with negatively charged oxygen atoms and metal cations ${ }^{6}$ (Figure $4 \mathrm{~b}$ ). The most pronounced shift was observed in the case of $\mathrm{Li}^{+}$ion as a result of having the highest charge density $\left(98 \mathrm{C} \mathrm{mm}^{-3}\right)$ within alkali metal ions. ${ }^{45}$ Here, we compared with the

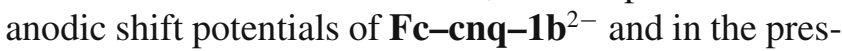
ence of 2.0 equiv. alkali metal ions. The semiquinone radical $\mathbf{F c}-\mathbf{c n q}-\mathbf{1} \mathbf{b}^{-}$product was almost not affected by alkali metal ions, indicating no ion pairing forma-

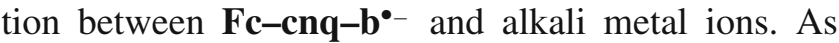
expected, almost no potential shift was also observed for the oxidized product $\mathbf{F c}^{+}-\mathbf{c n q}-\mathbf{1 b}$. The compound Fc-cnq-1a in the absence of alkali metal ions exhibited the cathodic peak potentials at $-1.92 \mathrm{~V}$ corresponding

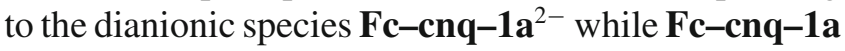


(a)

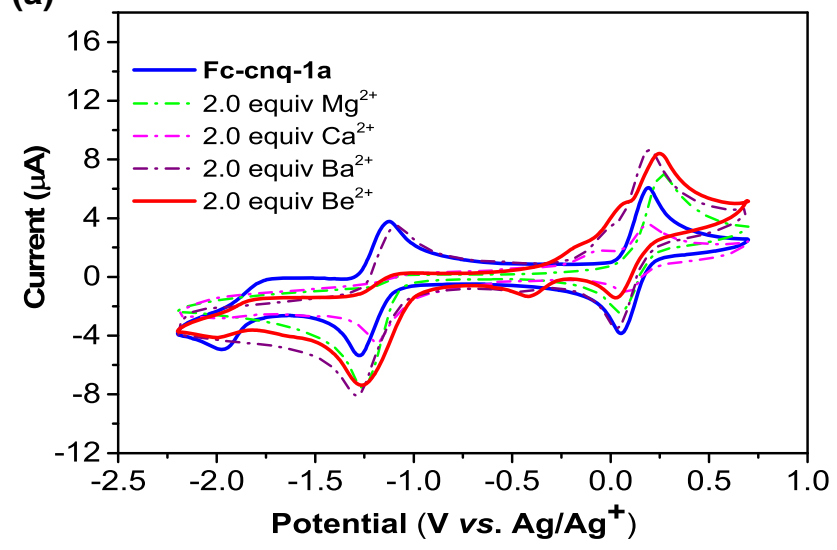

(b)

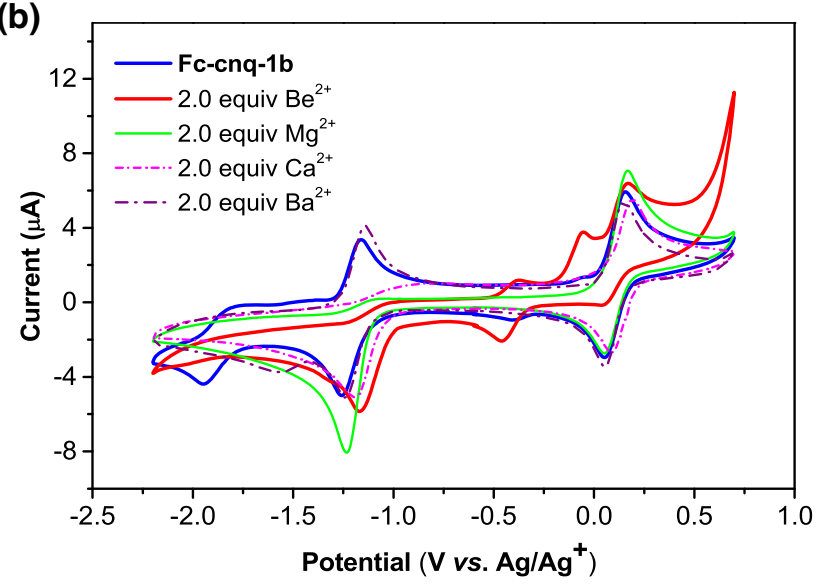

Figure 5. CVs of Fc-cnq-1a (a) and Fc-cnq-1b (b) in the presence of 2.0 equiv. alkaline earth metal $\left(\mathrm{Be}^{2+}, \mathrm{Mg}^{2+}, \mathrm{Ca}^{2+}\right.$, and $\mathrm{Ba}^{2+}$ ) salts in DMF solution containing $0.2 \mathrm{M} \mathrm{n}$ - $\mathrm{Bu}_{4} \mathrm{NClO}_{4}$ at scan rate of $0.100 \mathrm{~V} \mathrm{~s}^{-1}$, the concentration of $\mathbf{F c}-\mathbf{c n q}-\mathbf{1 a}$ and $\mathbf{F} \mathbf{c}-\mathbf{c n q} \mathbf{- 1 b}=5.0 \times 10^{-3} \mathrm{M}$. Working electrode: glassy carbon disk electrode (3.0 mm diameter).

in the presence of 2.0 equiv. $\mathrm{Li}^{+}, \mathrm{Na}^{+}, \mathrm{K}^{+}$and $\mathrm{Cs}^{+}$ ions, displayed the cathodic peak potentials at $-1.87 \mathrm{~V}$, $-1.75 \mathrm{~V},-1.85 \mathrm{~V}$ and $-1.81 \mathrm{~V}$, respectively for the same dianionic species. The differences of the cathodic peak potentials between $\mathbf{F c - c n q - 1 a}$ in the absence and presence of $\mathrm{Li}^{+}, \mathrm{Na}^{+}, \mathrm{K}^{+}$and $\mathrm{Cs}^{+}$ions were calculated as $0.05 \mathrm{~V}, 0.17 \mathrm{~V}, 0.07 \mathrm{~V}$ and $0.11 \mathrm{~V}$, respectively. It could be interpreted from the similarity of the $\mathrm{CV}$ responses of Fc-cnq-1a and Fc-cnq-1b toward alkali metal ions in the solution of DMF that alkali metal ion binding processes for $\mathbf{F c - c n q - 1 a}$ also proceed via the ion pairing formation as observed for Fc-cnq-1b. However, the peak potentials corresponding to the dianionic species $\mathbf{F c}-\mathbf{c n q}-\mathbf{1 a}^{2-}$ in the presence of $\mathrm{Li}^{+}$ion was slightly shifted to anodic site compared to that of Fc-cnq-1 $\mathbf{b}^{2-}$, which indicated that there was a weak ion pairing formation between $\mathrm{Li}^{+}$ion and the doubly

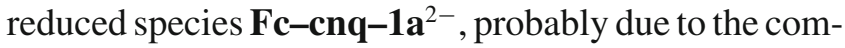
plexation between the crown ether unit in the sensor and $\mathrm{Li}^{+}$ion with small atomic radius $(73 \mathrm{pm}) .{ }^{45}$ The representative mechanism of the electrochemical processes for $\mathbf{F c - c n q - 1 a}$, and the ion pair formation between the dianion $\mathbf{F c}-\mathbf{c n q}-\mathbf{1 a}^{2-}$ and alkali metal ions $\left(\mathrm{Li}^{+}, \mathrm{Na}^{+}\right.$, $\mathrm{K}^{+}$and $\mathrm{Cs}^{+}$) in DMF are given in Scheme 1 .

The CVs obtained from voltammetric titrations of $\mathbf{F c}-$ cnq-1a and Fc-cnq-1b with alkaline earth metal $\left(\mathrm{Be}^{2+}\right.$, $\mathrm{Mg}^{2+}, \mathrm{Ca}^{2+}$ and $\mathrm{Ba}^{2+}$ ) perchlorates in DMF were represented in (Figure 5S-7S). Figure 5 shows the combined CVs of Fc-cnq-1a and Fc-cnq-1b in the presence of 2.0 equiv. alkaline earth metal perchlorates. As seen from Figure 5, Fc-cnq-1a and Fc-cnq-1b displayed almost similar electrochemical behavior in the presence of 2.0 equiv. alkaline earth metal $\left(\mathrm{Be}^{2+}, \mathrm{Mg}^{+2}, \mathrm{Ca}^{2+}\right.$ and $\mathrm{Ba}^{2+}$ ) ions, which strongly supports the pair formation between the reduced species of Fc-cnq-1a and alkaline earth metal ions as observed in the presence of alkali metal ions. The CVs of Fc-cnq-1a and Fc-cnq$\mathbf{1 b}$ in the presence of 2.0 equiv. $\mathrm{Ba}^{2+}$ ions (purple short dash-dot line in Figure 5) are similar to the CVs of these molecules in the presence of alkali metal ions. However, we did not observe the corresponding dianionic wave, indicating the formation of unstable dianionic species $\mathbf{F c - c n q - 1 a ^ { 2 - }}$ or $\mathbf{F c - c n q - 1 \mathbf { b } ^ { 2 - }}$. Although there are some similarities between voltammetric changes of the studied metal cations $\left(\mathrm{Be}^{2+}, \mathrm{Mg}^{2+}\right.$ and $\left.\mathrm{Ca}^{2+}\right)$, among them, especially, $\mathrm{Be}^{2+}$ ion has the strongest effect on the electrochemical reduction processes, probably due to its highest reactivity for the ion pairing interaction.

The voltammetric changes observed for Fc-cnq-1a and Fc-cnq-1b with an increasing amount of $\mathrm{Be}^{2+}$ ion (0-2.0 equiv.) are exhibited in Figure 6. The illustrative electrochemical mechanism corresponding to the ion pair formation reaction between $\mathrm{Be}^{2+}$ ion and the electrochemically reduced species of $\mathbf{F c - c n q - 1 a}$ is depicted in Scheme 2.

This mechanism can also be applied for Fc-cnq-1b in the same approach. In Figure 6 and Scheme 2, the cathodic and anodic waves in the absence of $\mathrm{Be}^{2+}$ ion were designated by Ic and Ia for the first reduction process, IIc and IIa for the second reduction process, and IIIc and IIIa for the oxidation process (blue solid line in Figure 6), respectively.

The CVs of Fc-cnq-1a and Fc-cnq-1b in the presence of 2.0 equiv. $\mathrm{Be}^{2+}$ ion are exhibited as a red solid line in Figures 5 and 6. As seen from Figure 6, a significant change in CVs of Fc-cnq-1a and Fc-cnq-1b was observed when they were titrated with an increasing amount of $\mathrm{Be}^{2+}$ ion in DMF. Most importantly, the dianionic waves (IIc and IIa) for the second reduction processes of $\mathbf{F c - c n q - 1 a}$ and $\mathbf{F c - c n q - 1 b}$ almost 
(a)

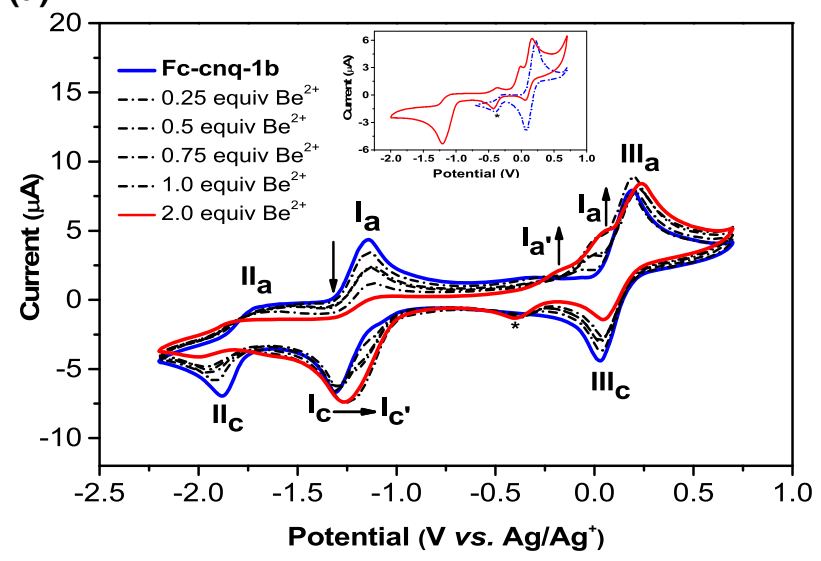

(b)

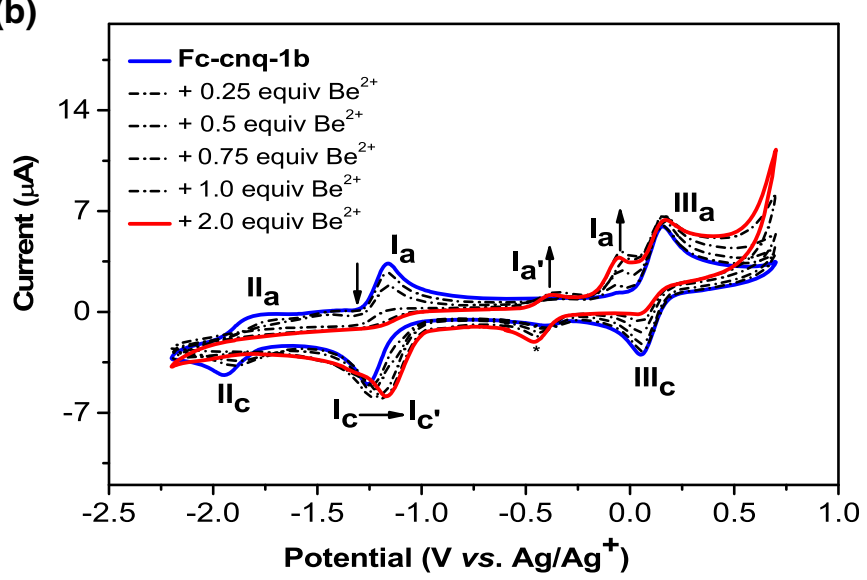

Figure 6. $\mathrm{CV}$ s of Fc-cnq-1a (a) and $\mathbf{F c - c n q - 1 b}$ (b) for increasing amount of $\mathrm{Be}^{2+}$ ion $(0-2.0$ equiv.) in DMF solution containing $0.2 \mathrm{M} n-\mathrm{Bu}_{4} \mathrm{NClO}_{4}$ at scan rate of $0.100 \mathrm{~V} \mathrm{~s}^{-1}$, the concentration of $\mathbf{F c}-\mathbf{c n q}-\mathbf{1 a}$ and $\mathbf{F c}-\mathbf{c n q}-\mathbf{1 b}=5.0 \times 10^{-3} \mathbf{M}$. Working electrode: glassy carbon disk electrode (3.0 mm diameter). Inset in Figure 6 (a) shows the CV of Fc-cnq-1a for 2.0 equiv. $\mathrm{Be}^{2+}$ ion (red solid line) and the $\mathrm{CV}$ of $\mathrm{Fc}-\mathrm{cnq}-1 \mathrm{a}$ for 2.0 equiv. $\mathrm{Be}^{2+}$ ion during anodic scan in the range of $-0.400 \mathrm{~V}$ to $0.700 \mathrm{~V}$ (blue dash line).

disappeared, clearly indicating the unstable doubly reduced products $\mathbf{F} \mathbf{c}-\mathbf{c n q}-\mathbf{- 1 \mathbf { a } ^ { 2 - }}$ and $\mathbf{F} \mathbf{c}-\mathbf{c n q}-\mathbf{1} \mathbf{b}^{2-}$ in the presence of $\mathrm{Be}^{2+}$ ion. As shown in Figure $6 \mathrm{a}$ and Scheme 2, the cathodic wave potential of Fc-cnq$1 \mathbf{a}^{\bullet-}$ (Ic), displayed at $-1.31 \mathrm{~V}$ in the absence of $\mathrm{Be}^{2+}$ ion, anodically shifted to $-1.25 \mathrm{~V}$ in the presence of $\mathrm{Be}^{2+}$ ion as a result of the ion pair formation between the monoan-

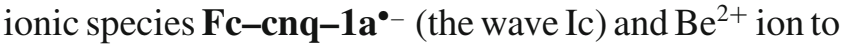
produce the product $\left[(\mathbf{F c}-\mathbf{c n q}-\mathbf{1 b})_{2}^{--}-\mathbf{B e}^{2+}\right]$ (the wave Ic'). The anodic wave of Fc-cnq-1a'- (Ia) for the first re-oxidation process gradually diminished depending on the increasing amount of $\mathrm{Be}^{2+}$, which reappeared as new anodic waves (Ia') at $-0.191 \mathrm{~V}$ and (Ia) at 0.051 corresponding to the products $\left[(\mathbf{F} \mathbf{c}-\mathbf{c n q}-\mathbf{1 a})^{\bullet}{ }^{-}-\mathbf{C l}\right]$ and Fc-cnq-1a, respectively.

Following Fc-cnq-1a irreversibly oxidized to the ferrocenium species $\mathbf{F c}^{+}$-cnq-1a at $E_{\mathrm{pa}}^{(\mathrm{Fc})}=0.224 \mathrm{~V}$ as result of decreasing cathodic wave (IIIc) and appearing new corresponding cathodic wave at $-0.453 \mathrm{~V}$, indicated as asterisk, which also clearly observed during scanning in the range of $-0.4 \mathrm{~V}$ to $0.7 \mathrm{~V}$ (inset in Figure 6 (a), blue dash line). Similar electrochemical behavior as depicted in Scheme 2 was also observed for Fc-cnq-1b under identical conditions. The maximum anodic shift for the first reduction processes of Fc-cnq-1a and Fc-cnq1b (the waves Ic') was observed for $\mathrm{Be}^{2+}$ ion within studied alkali and alkaline earth metals verifying that $\mathrm{Be}^{2+}$ ion has the highest reactivity for the ion pairing interaction for the electrochemically reduced products of Fc-cnq-1a and Fc-cnq-1b. The CVs obtained from voltammetric titrations of $\mathbf{F c - c n q - 1 b}$ with varying transition metal $\left(\mathrm{Ni}^{+2}, \mathrm{Co}^{+2}, \mathrm{Zn}^{+2}\right.$ and $\left.\mathrm{Cu}^{+2}\right)$ perchlorates in DMF were separately represented (Figure $8 \mathrm{~S}$,
Supplementary Information) in DMF at the scan rate of $0.100{\mathrm{~V} . \mathrm{s}^{-1}}^{-}$containing $0.2 \mathrm{M}$ TBAP supporting electrolyte. As seen from Figure 8S (Supplementary Information), no visible change was observed on the current or the formal potentials of redox processes corresponding to Fc-cnq-1b.

\subsection{In situ spectroelectrochemical experiment}

In this study, $\mathbf{F c - c n q - 1 a}$ as a naphthoquinone derivative was studied for the first time by in situ spectroelectrochemical experiments in a thin-layer cell ${ }^{4,5,38,42,46}$ in order to verify the ion-pair formation reaction between $\mathrm{Be}^{2+}$ ion and the electrochemically reduced species of Fc-cnq-1a that was observed during the voltammetric titration studies above. The experiment was performed for $\mathbf{F c - c n q - 1 a}$ in the absence and presence of $\mathrm{Be}^{2+}$ ion to compare UV-vis spectra of the reduced products Fc-cnq-1 $\mathbf{b}^{-\boldsymbol{}}$ - and the ion pairing complex [(Fc-cnq$\mathbf{1 a})_{2}^{\mathbf{0}}-\mathbf{B e}^{\mathbf{2}+}$ ]. Time-resolved UV-vis spectral changes of Fc-cnq-1a during the first oxidation at $\mathrm{E}_{\text {app }}=0.700 \mathrm{~V}$ and the first reduction at $\mathrm{E}_{\text {app }}=-1.75 \mathrm{~V}$ in $\mathrm{DMF}$ solution containing $0.2 \mathrm{M} \mathrm{n}-\mathrm{Bu}_{4} \mathrm{NClO}_{4}$ are presented in Figure 7.

The spectra of the oxidized and the reduced products presented characteristic view for ferrocenium $\mathbf{F c}^{+}$ cnq-1a and semiquinone radical anion Fc-cnq-1a ${ }^{\bullet-}$ which were well-consistent with previously described ferrocene-benzoquinone/naphthoquinone systems. ${ }^{4,5}$

When we recorded the time-resolved UV-vis spectral changes of Fc-cnq-1a in the presence of excess amount of $\mathrm{Be}^{2+}$ in DMF solution during the first reduction process at $E_{\text {app }}=-1.75 \mathrm{~V}$, noticeable changes in 
<smiles>CCCC1=C(c2ccccc2)C(=O)c2ccc3c(c2C1=O)OCCOCCO3</smiles>

Fc-cnq-1a<smiles>CCCCC</smiles><smiles></smiles>

IIIa

$\mathrm{Fc}^{+}$-enq-1a

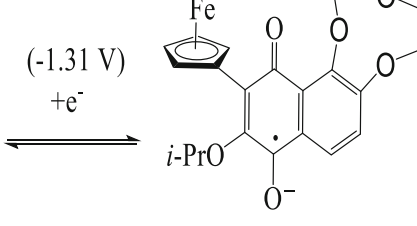

Ic .-

Fc-cnq-1a
$(-1.25 \mathrm{~V})$

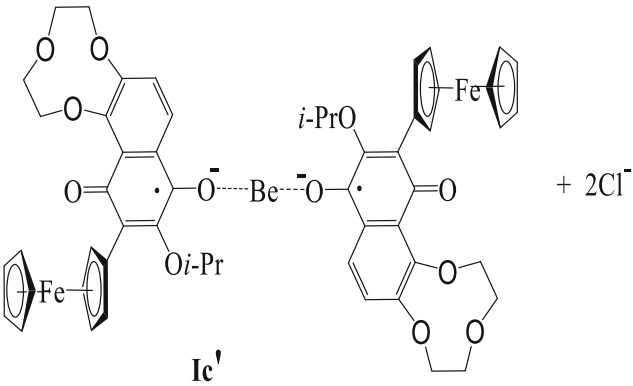

$$
\left[(\text { Fc-cnq-1ä })_{2}-\mathrm{Be}^{2+}\right]
$$$$
-e^{-} \mid(-0.191) \mathrm{V}
$$

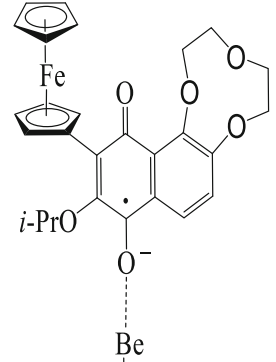

$\mathrm{Cl}$

Ia'

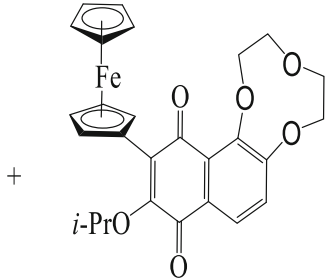

Ia
Fe-cnq-1a

\section{[(Fc-cnq-1a-Cl]}

Scheme 2. The electrochemical mechanism corresponding to ion pair formation reaction between $\mathrm{Be}^{2+}$ ion and the electrochemically reduced species of $\mathbf{F c - c n q - 1 a . ~}$

(a)

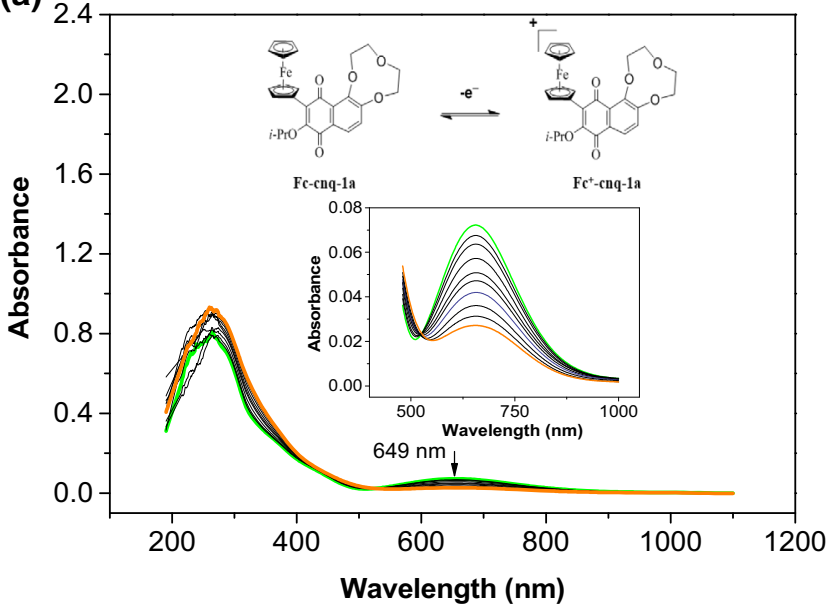

(b)

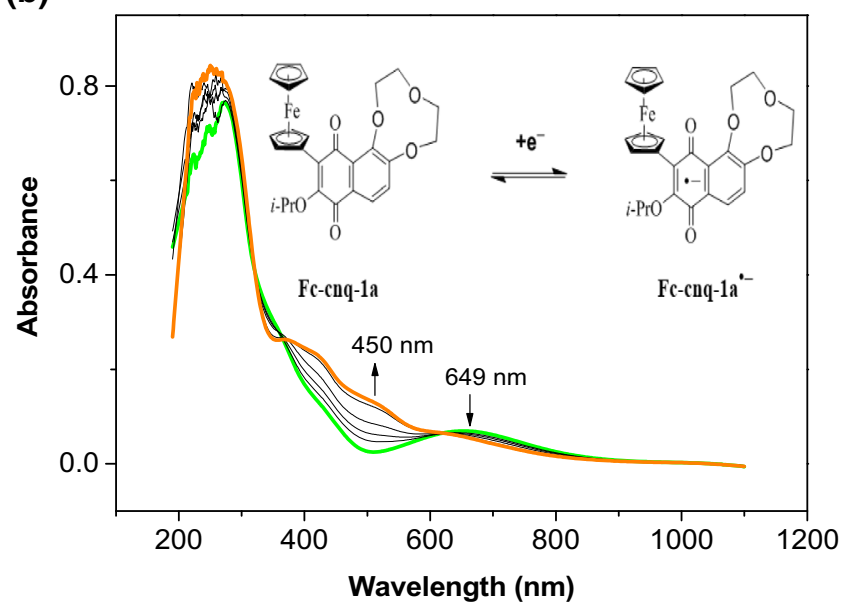

Figure 7. Time-resolved UV-vis spectral changes of $\mathbf{F c - c n q - 1 a}$ during the first oxidation at $E_{\text {app }}=\mathbf{0 . 7 0 0} \mathbf{V}$ (a) and the first reduction at $E_{\text {app }}=-1.75 \mathrm{~V}$ (b) in DMF solution containing $0.2 \mathrm{M} n-\mathrm{Bu}_{4} \mathrm{NClO}_{4}$. Inset: the magnified spectra in the range of $480 \mathrm{~nm}-100 \mathrm{~nm}$. Arrows mark the direction of absorbance change. 


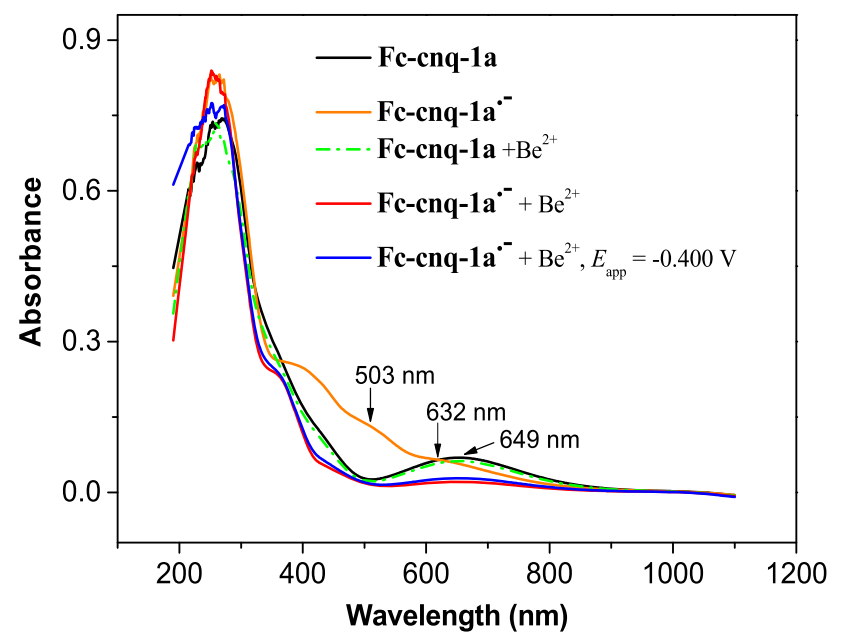

Figure 8. Time-resolved UV-vis spectral changes of Fc-cnq-1a in the presence of $\mathrm{Be}^{2+}$ ion during the first reduction at $E_{\text {app }}=-1.75 \mathrm{~V}$ in DMF solution containing $0.2 \mathrm{M}$ $n-\mathrm{Bu}_{4} \mathrm{NClO}_{4}$.

the intensity for the spectrum of the reduced product $\left[(\mathrm{Fc}-\mathrm{cnq}-1 \mathrm{a})_{2}^{\bullet-}-\mathrm{Be}^{2+}\right]$ (red solid line) in the presence of $\mathrm{Be}^{2+}$ ion were observed, compared to the spectrum of the reduced form (orange solid line) Fc-cnq-1 $\mathbf{a}^{\bullet-}$ in the absence of $\mathrm{Be}^{2+}$ ion (Figure 8). Additionally, the original spectrum of Fc-cnq-1a (green solid line) could not be recovered upon re-oxidation operation $\left(E_{\text {app }}=-0.400 \mathrm{~V}\right)$ during the spectroelectrochemical timescale. These results clearly confirmed that the semiquinone radical anion $\mathbf{F c}-\mathbf{c n q}-\mathbf{1 a}^{\bullet-}$ and $\mathrm{Be}^{2+}$ ion resulted in the ion pair formation [(Fc-cnq-1a $\left.)_{2}^{\bullet-}-\mathrm{Be}^{2+}\right]$ which did not remain chemically stable throughout the experiment. By this way, the ion pair formation reaction between $\mathrm{Be}^{2+}$ ion and the electrochemically reduced species was for the first time observed by in situ spectroelectrochemical experiments.

\subsection{Electrochemical sensing $B e^{2+}$ ion}

These results clearly indicate that Fc-cnq-1a or Fccnq-1b can selectively sense $\mathrm{Be}^{2+}$ ion among several metal ions studied here by voltammetric titration technique using SWV, through the strong ion pair formation reaction between the electrochemically reduced monoanion radicals and $\mathrm{Be}^{2+}$ ions. In the first part of this study, as shown in Figure 6 recorded by CV, the

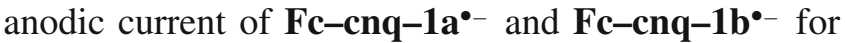
the first reduction process gradually decreased depending on the increasing amount of $\mathrm{Be}^{2+}, \mathrm{Mg}^{+2}$ and $\mathrm{Ca}^{+2}$.

It can be seen from Figure 9 that the first anodic peak corresponding to the radical $\mathbf{F c}-\mathbf{c n q}-\mathbf{1 a}^{\bullet-}$ gradually decreases depending on the increasing amount of $\mathrm{Be}^{2+}$, where the plot of $\Delta I \mathrm{a}$ vs $\left[\mathrm{Be}^{2+}\right]$ ion for the

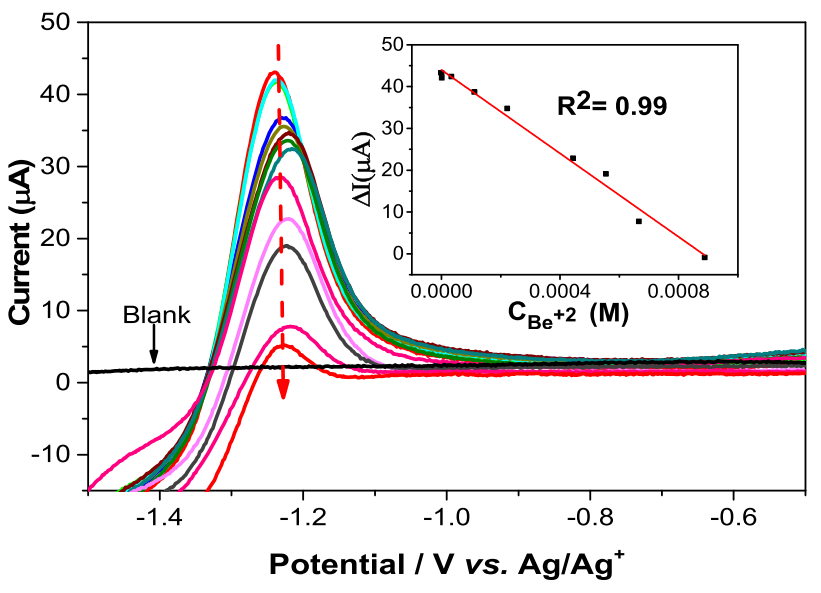

Figure 9. SWV changes of Fc-cnq-1a $\left(5.0 \times 10^{-3} \mathrm{M}\right)$ titrated with $\mathrm{Be}^{2+}$ ion $\left(0-2.5 \times 10^{-3} \mathrm{M}\right)$ at $0.100 \mathrm{~V} \mathrm{~s}^{-1}$ scan rate in DMF/TBAP. Inset: the plot of $\triangle I$ a $v s\left[\mathrm{Be}^{2+}\right]$ for $\mathrm{SWV}$, Pulse PH/PW: 0.025 V for 0.01 s; Step Height: $2.00 \mathrm{mV}$; Scan rate: $0.100 \mathrm{~V} \mathrm{~s}^{-1}$.

current is inserted in Figure 9. Linear range of the sensor Fc-cnq-1a for determining $\mathrm{Be}^{2+}$ ion via SWV technique was found in the range of $1.1 \times 10^{-6} \mathrm{M}-8.8 \times$ $10^{-4} \mathrm{M}$. The linear regression equation for $\mathrm{Be}^{2+}$ is $\mathrm{y}=-49876 \mathrm{x}+44.0$ with $\mathrm{R}^{2}=0.986$. The limit of detection (LOD $=3 \alpha /$ slope $)^{47-50}$ was calculated to be $3.9 \times 10^{-7} \mathrm{M}(3.6 \mathrm{ppb})$ which is below the critical $\mathrm{Be}^{2+}$ level in water (4 ppb) as reported by World Health Organization (WHO). In the present case, $\alpha(0.00634)$ is the standard deviation for 10 parallel determinations of ligand solution.

On the other hand, $\mathrm{Fc}-\mathrm{cnq}-1 \mathrm{a}$ was titrated with $\mathrm{Mg}^{2+}$ and $\mathrm{Ca}^{+2}$ under the same experimental conditions. As seen from Figures 10a and $b$, the first anodic peaks of Fccnq-1 $a^{\bullet-}$ gradually decreased depending on increasing amounts of $\mathrm{Mg}^{2+}$ and $\mathrm{Ca}^{+2}$, respectively, where the plots of $\Delta I \mathrm{a} v s\left[\mathrm{Mg}^{2+}\right]$ and $\left[\mathrm{Ca}^{2+}\right]$ ions for the anodic waves are inserted in Figures 10a and $\mathrm{b}$. Linear ranges of the sensor Fc-cnq-1a for sensing $\mathrm{Mg}^{2+}$ and $\mathrm{Ca}^{+2}$ ions via SWV technique were found in the range of $4.1 \times 10^{-5} \mathrm{M}$ $-1.9 \times 10^{-3} \mathrm{M}$, and $2.1 \times 10^{-5} \mathrm{M}-4.2 \times 10^{-4} \mathrm{M}$, respectively. The sensitivity sequence of $\mathrm{Fc}-\mathrm{cnq}-1 \mathrm{a}$ is as follows: $\mathrm{Be}^{+2}>\mathrm{Ca}^{+2}>\mathrm{Mg}^{+2}$ in view of the linear ranges, indicating that $\mathbf{F c - c n q - 1 a}$ can be exploited for selective electrochemical recognition of $\mathrm{Be}^{2+}, \mathrm{Mg}^{+2}$ and $\mathrm{Ca}^{+2}$ ions as well as more sensitive performance for ultra-trace amount of $\mathrm{Be}^{2+}$ among the other metal ions. The titration experiments of Fc-cnq-1 $\mathbf{b}$ in the presence of $\mathrm{Be}^{+2}, \mathrm{Ca}^{+2}$ and $\mathrm{Mg}^{+2}$ were also performed by the SWV, which showed similar electrochemical responses with what was observed for Fc-cnq-1a (Figure 9S, Supplementary Information). The linear range of $\mathrm{Fc}-$ cnq-1b for determining $\mathrm{Be}^{2+}$ ion via SWV technique 
(a)

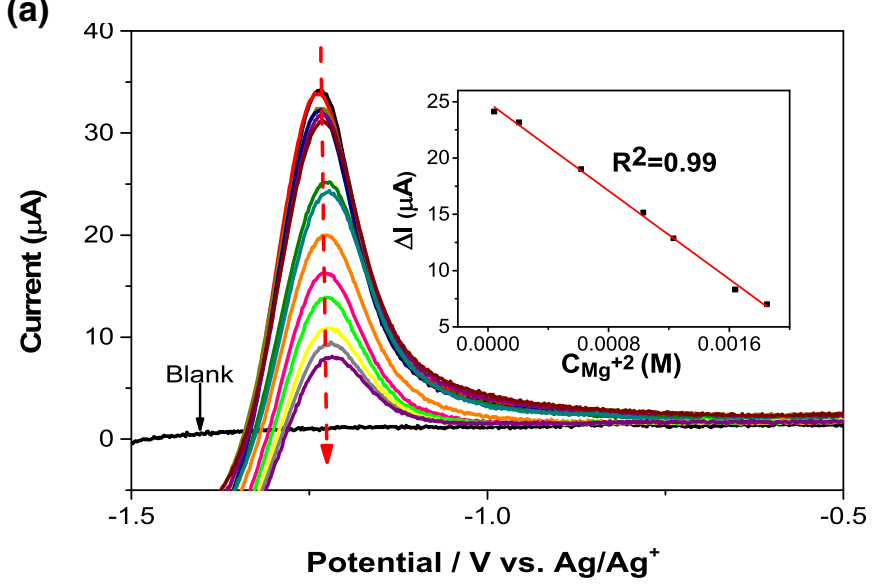

(b)

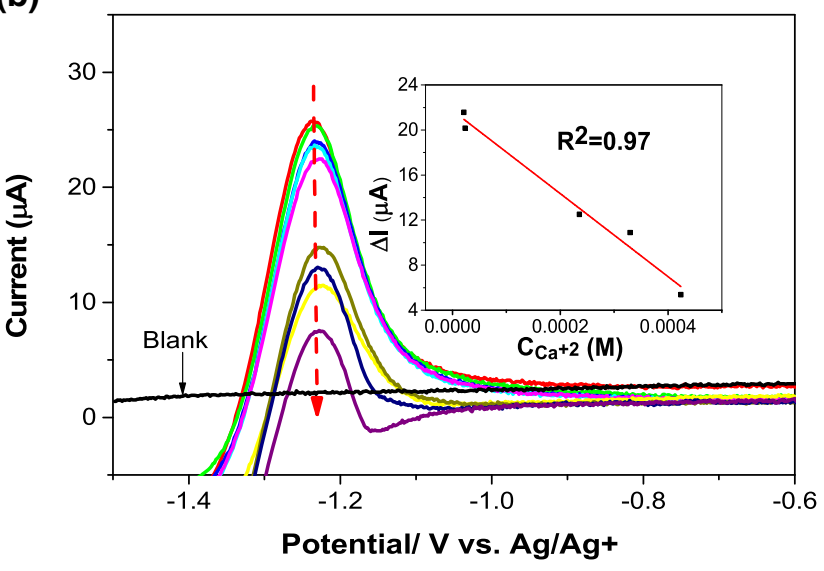

Figure 10. SWV changes of Fc-cnq-1a $\left(5.0 \times 10^{-3} \mathrm{M}\right)$ titrated with $\mathrm{Mg}^{2+}$ and $\mathrm{Ca}^{+2}\left(0-2.0 \times 10^{-3} \mathrm{M}\right)$ ions at 0.100 V.s ${ }^{-1}$ scan rate in DMF/TBAP. Inset a: the plot of $\Delta I$ a vs. $\left[\mathrm{Mg}^{2+}\right]$ for SWV. Inset b: the plot of $I$ a vs. $\left[\mathrm{Ca}^{2+}\right]$ for SWV. Pulse PH/PW: 0.025 V for $0.01 \mathrm{~s}$; Step Height: $2.00 \mathrm{mV}$; Scan rate: $0.100 \mathrm{~V} \mathrm{~s}^{-1}$.

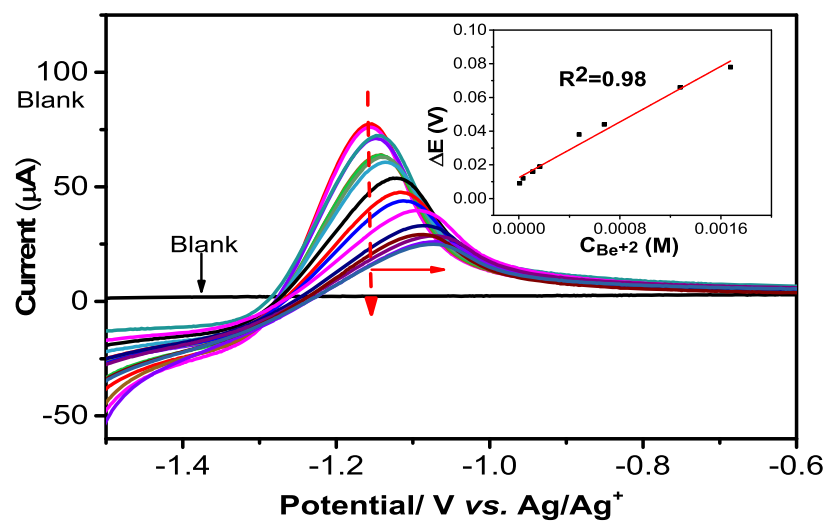

Figure 11. SWV changes of Fc-cnq-1b $\left(5.0 \times 10^{-3} \mathrm{M}\right)$ titrated with $\mathrm{Be}^{2+}$ ion $\left(0-2.5 \times 10^{-3} \mathrm{M}\right)$ at $0.100 \mathrm{~V} \cdot \mathrm{s}^{-1}$ scan rate in DMF/TBAP. Inset: the plot of $\Delta E^{(1)} v s\left[\mathrm{Be}^{2+}\right]$ for SWV Pulse PH/PW: 0.025 V for 0.01 s; Step Height: $2.00 \mathrm{mV}$; Scan rate: $0.100 \mathrm{~V} \mathrm{~s}^{-1}$.

was found in the range of $1.1 \times 10^{-6} \mathrm{M}-1.7 \times 10^{-3} \mathrm{M}$ and LOD was calculated to be $4.7 \times 10^{-7} \mathrm{M}(4.5 \mathrm{ppb})$. The linear ranges of $\mathbf{F c - c n q - 1 b}$ for sensing $\mathrm{Mg}^{2+}$ and $\mathrm{Ca}^{+2}$ ions were found in the range of $2.5 \times 10^{-5} \mathrm{M}$ $-1.4 \times 10^{-3} \mathrm{M}$ and $1.3 \times 10^{-6} \mathrm{M}-6.3 \times 10^{-4} \mathrm{M}$, respectively. The sensitivity sequence for these ions in case of Fc-cnq-1b is similar to that was observed for Fc-cnq1a. Unlike the first anodic peak of Fc-cnq-1 $\mathrm{a}^{\bullet-}$, that of Fc-cnq-1 $\mathbf{b}^{\bullet-}$ gradually shifted to anodic site depending on the increasing amount of $\mathrm{Be}^{2+}$, which was not observed for $\mathrm{Mg}^{+2}$ and $\mathrm{Ca}^{+2}$ (Figure 11). Inset in Figure 11 shows the plot of $\Delta E^{(1)} v s\left[\mathrm{Be}^{2+}\right]$ ion for the anodic waves. The linear range of the sensor Fc-cnq-1b for determining $\mathrm{Be}^{2+}$ ion based on the first anodic wave was found in the range of $5.6 \times 10^{-6} \mathrm{M}-1.7 \times 10^{-3} \mathrm{M}$, which is close to the range calculated with the plot of $\Delta I v s\left[\mathrm{Be}^{2+}\right]$ ion.

\section{Conclusions}

In summary, the mechanistic aspects of the ion pair formation between the electrochemically reduced monoanion radical and dianion products of ferrocenyl naphthoquinones (Fc-cnq-1a and $\mathbf{F c - c n q - 1 b}$ ) and several metal ions were for the first time studied in detail for a large number of metal ions using CV, SWV and in situ spectroelectrochemistry. The experiments indicated that alkali metal $\left(\mathrm{Li}^{+}, \mathrm{Na}^{+}, \mathrm{K}^{+}\right.$and $\left.\mathrm{Cs}^{+}\right)$and $\mathrm{Ba}^{2+}$ metal ions have an impact on the dianions $\mathrm{Fc}-\mathrm{cnq}-1 \mathrm{a}^{2-} / \mathrm{Fc}-\mathrm{cnq}-$ $1 b^{2-}$ to a certain extent but no effect on the semiquinone radicals $\mathbf{F c}-\mathbf{c n q}-\mathbf{1 a}^{\bullet}-\mathbf{F c}-\mathbf{c n q}-\mathbf{1 b}^{\bullet-}$ which are distinctly influenced by $\mathrm{Be}^{2+}, \mathrm{Mg}^{2+}$ and $\mathrm{Ca}^{2+}$ in DMF due to the strong ion pair formation between the electrochemically reduced monoanion radicals and these ions. On the other hand, the most pronounced effect on the ion-pair formation was observed for $\mathrm{Be}^{2+}$ among studied metal ions, which could be facilitated to selectively sense $\mathrm{Be}^{2+}$ ion by SWV titration technique for the first time based on the strong ion pair formation reaction between the radicals and $\mathrm{Be}^{2+}$. The experiments demonstrated that the sensitivity sequence of the radicals is as follows: $\mathrm{Be}^{+2}>\mathrm{Ca}^{+2}>\mathrm{Mg}^{+2}$, indicating that Fc-cnq-1a and Fc-cnq-1b can be exploited for electrochemical recognition of $\mathrm{Be}^{2+}, \mathrm{Mg}^{+2}$ and $\mathrm{Ca}^{+2}$ ions as well as more sensitive performance for ultra-trace amount of $\mathrm{Be}^{2+}$ among the other metal ions. LOD of $\mathrm{Fc}-$ cnq-1a for $\mathrm{Be}^{2+}\left(3.9 \times 10^{-7} \mathrm{M}(3.6 \mathrm{ppb})\right)$ is lower than that of Fc-cnq-1b $\left(4.7 \times 10^{-7} \mathrm{M}(4.5 \mathrm{ppb})\right)$, and below the critical $\mathrm{Be}^{2+}$ level in water $(4.0 \mathrm{ppb})$ as reported by World Health Organization (WHO). The new sensors $\mathbf{F c - c n q - 1 a}$ and $\mathbf{F c - c n q - 1 \mathbf { b }}$ with these LOD values have a moderate analytical performance for $\mathrm{Be}^{2+}$ ion determination compared to the previous sensors based 
on electrochemical methods (Table S1, Supplementary Information).

\section{Supplementary Information (SI)}

The CVs obtained from voltammetric titrations of $\mathbf{F c - c n q - 1 a}$ and $\mathbf{F} \mathbf{c}-\mathbf{c n q}-\mathbf{1 b}$ with alkali metal $\left(\mathrm{Li}^{+}, \mathrm{Na}^{+}, \mathrm{K}^{+}\right.$, and $\left.\mathrm{Cs}^{+}\right)$ perchlorates in DMF were separately represented in (Figure $1 \mathrm{~S}-4 \mathrm{~S}$ ). The CVs obtained from voltammetric titrations of Fc-cnq-1a and $\mathbf{F c - c n q - 1 b}$ with alkaline earth metal $\left(\mathrm{Mg}^{2+}\right.$, $\mathrm{Ca}^{2+}$ and $\mathrm{Ba}^{2+}$ ) perchlorates (0-2.0 equiv.) in DMF were represented in Figure 5S-7S. The CVs obtained from voltammetric titrations of $\mathrm{Fc}-\mathrm{cnq}-1 \mathrm{~b}$ with varying transition metal $\left(\mathrm{Ni}^{+2}, \mathrm{Co}^{+2}, \mathrm{Zn}^{+2}\right.$ and $\left.\mathrm{Cu}^{+2}\right)$ perchlorates in DMF were separately represented (Figure $8 \mathrm{~S}$ ) in DMF at the scan rate of $0.100 \mathrm{~V} . \mathrm{s}^{-1}$ containing $0.2 \mathrm{M}$ TBAP supporting electrolyte. The titration experiments of $\mathbf{F} \mathbf{c}-\mathbf{c n q} \mathbf{- 1} \mathbf{b}$ in the presence of $\mathrm{Be}^{+2}, \mathrm{Ca}^{+2}$ and $\mathrm{Mg}^{+2}$ were performed by the SWV (Figure 9S).

\section{Acknowledgements}

The authors gratefully acknowledge financial support from The Scientific and Technological Research Council of Turkey (TUBITAK) (Project Number: 113Z309) and Research Fund of the Istanbul Technical University. (Project Number: 1312).

\section{References}

1. Chambers J Q 1988 In The Chemistry of the Quinonoid Compounds Z Rappoport and Z Patai (Eds.) (New York: Wiley) Vol. 2 Ch. 12 p. 719

2. Lehmann M W and Evans D H 2001 Mechanism of the electrochemical reduction of 3,5-di-tert-butyl-1,2benzoquinone. Evidence for a concerted electron and proton transfer reaction involving a hydrogen-bonded complex as reactant J. Phys. Chem. B $\mathbf{1 0 5} 8877$

3. Jin B, Huang J, Zhao A, Zhang S, Tian Y and Yang J 2010 Direct evidence of hydrogen-bonding and/or protonation effect on p-benzoquinone electrochemical reduction by in situ IR spectroelectrochemical study J. Electroanal. Chem. 650116

4. Dagdevren M, Yilmaz I, Yucel B and Emirik M 2015 Novel ferrocenyl naphthoquinone fused crown ether as a multisensor for water determination in acetonitrile and selective cation binding J. Phys. Chem. B 11912464

5. Yucel B, Sanli B, Soylemez H and Yilmaz I 2011 Synthesis and electro-spectroelectrochemistry of ferrocenyl naphthoquinones Tetrahedron 671406

6. Hoshino T, Oyama M and Okazaki S 2000 Substituent effect on ion pair formation reactions between 1,4-benzoquinone derivative anion radicals and metal cations Electroanalysis 121373

7. Oyama M, Takei A and Okazaki S 1995 Direct observation of ion pair formation between 2,3-dichloro-5,6dicyanobenzoquinone dianion and sodium ion J. Chem. Soc. Chem. Commun. 181909

8. Oyama M, Marken F, Webster R D, Cooper J A, Compton R G and Okazaki S 1998 Ion pair formation between the electrogenerated 2,3-dichloro-5,6-dicyano1,4-benzoquinone dianion and the sodium ion at platinum surfaces J. Electroanal. Chem. 451193

9. Oyama M, Webster R D, Suárez M, Marken F, Compton R G and Okazaki S 1998 Mechanistic aspects of the electrochemical reduction of 7,7,8,8-tetracyanoquinodimethane in the presence of $\mathrm{Mg}^{2+}$ or $\mathrm{Ba}^{2+}$ J. Phys. Chem. B 1026588

10. Alcay Y, Yavuz O, Gelir A, Kirlangic Atasen S, Karaoglu K, Yucel B, Şenyurt Tuzun N and Yilmaz I 2018 New ferrocenyl naphthoquinone fused crown ether chemosensors: Highly selective, kinetically and regio controlled colorimetric, beryllium ion recognition J. Organomet. Chem. 868131

11. Devaraj S, Saravanakumar D and Kandaswamy M 2007 Dual chemosensing properties of new anthraquinone-based receptors toward fluoride ions Tetrahedron 483077

12. Costentin C 2008 Electrochemical approach to the mechanistic study of proton-coupled electron transfer Chem. Rev. 1082145

13. Beer P D, Gale P A and Chen G Z 1999 Mechanisms of electrochemical recognition of cations, anions and neutral guest species by redox-active receptor molecules Coord. Chem. Rev. 185-186 3

14. Boulas P L, Gómez-Kaifer M and Echegoyen L 1998 Electrochemistry of supramolecular systems Angew. Chem. Int. Ed. 37216

15. Wang J, Thongngamdee S and Lu D 2006 Adsorptive stripping voltammetric measurements of trace berllyium at the mercury film electrode Anal. Chim. Acta $\mathbf{5 6 4} 248$

16. McCanlies E C, Kreiss K, Andrew M and Weston A 2003 HLA-DPB 1 and chronic beryllium disease: A huge review Am. J. Epidemiol. 157388

17. Stoeckle J D, Hardy H L and Weber A L 1969 Chronic beryllium disease: Long-term follow-up of sixty cases and selective review of the literature Am. J. Med. 46545

18. Sawyer R T, Day B J, Fadok V A, Chiarappa-Zucca M, Maier L A, Fontenot A P, Silveira L and Newman L S 2004 Beryllium-ferritin: Lymphocyte proliferation and macrophage apoptosis in chronic beryllium disease $\mathrm{Am}$. J. Respir. Cell Mol. Biol. 31470

19. Reeves A L, Deitch D and Vorwald A J 1967 Beryllium carcinogenesis. I. Inhalation exposure of rats to beryllium sulfate aerosol Cancer Res. 27439

20. Meyer K C 1994 Beryllium and lung disease Chest 106942

21. IARC International Agency for Research on Cancer 1993 Beryllium, cadmium, mercury, and exposures in the glass manufacturing industry. IARC monographs on the evaluation of carcinogenic risks to humans (Lyon, France)

22. WHO World Health Organization 2001 Beryllium and beryllium compounds. Concise international chemical assessment document No. 32 Geneva

23. Sandell E B and Onishi H 1978 Photometric Determination of Trace Metals Part $14^{\text {th }}$ edn. (New York: Wiley)

24. Vin Y Y and Khopkar S M 1998 Extractionchromatographic separation of beryllium with bis(2ethylhexyl)phosphoric acid Analyst 113175

25. Agnihotri N K, Singh H B, Sharma R L and Singh V K 1993 Simultaneous determination of beryllium and aluminium in mixtures using derivative Talanta $\mathbf{4 0} 415$ 
26. Snell F D and Hilton C L 1968 Encyclopedia of Industrial Chemical Analysis (New York: Wiley) Vol. 7 pp. 112-115

27. Shaw M J, Hill S J, Jones $P$ and Nesterenko $P$ N 2000 Determination of beryllium in a stream sediment by high-performance chelation ion chromatography $J$. Chromatogr. A 876127

28. Matsumiya H and Hoshino H 2003 Selective determination of Beryllium(II) Ion at picomole per decimeter cubed levels by kinetic differentiation mode reversedphase high-performance liquid chromatography with fluorometric detection using 2-(2'-hydroxyphenyl)10-hydroxybenzo[H]quinoline as precolumn chelating reagent Anal. Chem. 75413

29. Bashir W and Paull B 2001 Sensitive and selective ion chromatographic method for the determination of trace beryllium in water samples J. Chromatogr. A 910301

30. Snell F D 1978 Beryllium In Photometric and Fluorometric Methods of Analysis Metals (New York: Wiley) Part 1 pp. 661-701

31. Measures C I and Edmond J M 1986 Determination of beryllium in natural waters in real time using electron capture detection gas chromatography Anal. Chem. 582065

32. Burguera J L, Burguera M, Rondon C, Carrero P, Brunetto M R and Petit de Pena Y 2000 Determination of beryllium in natural and waste waters using on-line flow-injection preconcentration by precipitation/dissolution for electrothermal atomic absorption spectrometry Talanta $\mathbf{5 2} 27$

33. Štěpnička P (Ed.) 2008 Ferrocenes: Ligands, Materials and Biomolecules (New York: Wiley)

34. Macháčková L and Žemberyová M 2012 Cloud point extraction for preconcentration of trace beryllium and chromium in water samples prior to electrothermal atomic absorption spectrometry Anal. Methods 44042

35. Wang J and Tian B 1992 Trace measurements of beryllium by adsorptive stripping voltammetry and potentiometry Anal. Chim. Acta 270137

36. Sun C, Wang J, Hu W and Xie T 1992 Adsorption voltammetry of beryllium in the presence of 4-[(4-diethylamino-2-hydroxyphenyl)azo]5hydroxynaphthalene-2,7-disul phonic acid (Beryllon III) Anal. Chim. Acta 259319

37. Jose R, Datta P and Sreeja B 2017 Fabrication of anchored complexes as electrodes for sensing heavy metal ions by electrochemical method Oriental. J. Chem. 331438

38. Lin X Q and Kadish K M 1985 Vacuum-tight thin-layer spectroelectrochemical cell with a doublet platinum gauze working electrode Anal. Chem. 571498
39. Laviron E 1986 Electrochemical reactions with protonations at equilibrium: Part XIII. Experimental study of the homogeneous electron exchange in quinone/dihydroquinone systems J. Electroanal. Chem. 208357

40. Peover M E 1967 In Electroanalytical Chemistry A J Bard (Ed.) (New York: M. Dekker) Vol. 2 p. 1

41. Laviron E 1984 Electrochemical reactions with protonations at equilibrium: Part XII. The $2 \mathrm{e}^{-}, 2 \mathrm{H}^{+}$homogeneous isotopic electron exchange reaction (nine-member square scheme) J. Electroanal. Chem. 16929

42. Yilmaz I 2008 In situ monitoring of metallation of metal-free phthalocyaninevia UV-Vis and steady-state fluorescence techniques. Thin-layer UV-Vis and fluorescence spectroelectrochemistry of a new non-aggregating and electrochromic manganese $(3+)$ phthalocyanine $\mathrm{New}$ J. Chem. 3237

43. Kadish K M, Nakanishi T, Gürek A, Ahsen V and Yilmaz I 2001 Electrochemistry of a double-decker lutetium(III) phthalocyanine in aqueous media. The first evidence for five reductions J. Phys. Chem. B $\mathbf{1 0 5} 9817$

44. Bard A J and Faulkner L R 2001 Electrochemical Methods: Fundamentals and Applications $2^{\text {nd }}$ edn. (New York: Wiley)

45. Petrucci R H, Herring F G, Madura J D and Bissonnette C 2010 General Chemistry Principles and Modern Applications $10^{\text {th }}$ edn. (Canada, Toronto) p. 921

46. Yilmaz I, Arslan S, Guney S and Becerik I 2007 Synthesis, electro-spectroelectrochemical characterization and electrocatalytic behavior towards dioxygen reduction of a new water-soluble cobalt phthalocyanine containing naphthoxy-4-sulfonic acid sodium salt Electrochim. Acta 526611

47. Rocha D P, Cardoso R M, Mendonça D M H, Richter E M, Silva S G, Batista A D and Munoz R A A 2018 Solenoid micro-pumps: A new tool for sample introduction in batch injection analysis systems with electrochemical detection Electroanalysis 30180

48. Rocha D P, Cardoso R M, Mendonça D M H, Richter E M, Silva S G, Batista A D and Munoz R A A 2018 Solenoid micro-pumps: A new tool for sample introduction in batch injection analysis systems with electrochemical detection Electroanalysis 30180

49. Desimoni E and Brunetti B 2013 Presenting analytical performances of electrochemical sensors. Some suggestions Electroanalysis 251645

50. Lin X, Lu Z, Zhang Y, Liu, Mo G, Li J and Ye J 2018 A glassy carbon electrode modified with a bismuth film and laseretched graphene for simultaneous voltammetric sensing of $\mathrm{Cd}(\mathrm{II})$ and $\mathrm{Pb}(\mathrm{II})$ Microchim. Acta 185 438 